RESEARCH ARTICLE

\title{
Generation of a recombinant Sendai virus that is selectively activated and lyses human tumor cells expressing matrix metalloproteinases
}

\author{
H Kinoh ${ }^{1,3}$, M Inoue ${ }^{1,3}$, K Washizawa ${ }^{1}$, T Yamamoto ${ }^{1}$, S Fujikawa ${ }^{1}$, Y Tokusumi ${ }^{1}$, A Iida ${ }^{1}$, Y Nagai ${ }^{2}$ and \\ M Hasegawa ${ }^{1}$ \\ ${ }^{1}$ DNAVEC Research Inc., Kannondai, Tsukuba-shi, Ibaraki, Japan; and ${ }^{2}$ Toyama Institute of Health, Nakataigouyama, Kosugi-machi, \\ Imizu-gun, Toyama, Japan
}

\begin{abstract}
Malignant tumor cells often express matrix metalloproteinases (MMPs) at a high level to enable their dissemination and metastasis. Sendai virus (SeV), a nonsegmented negative strand RNA virus, spreads in the target tissues in vivo via cleavage activation of the viral fusion glycoprotein by a tissue-specific, trypsin-like enzyme. By deleting the viral matrix protein, we previously generated a recombinant SeV that does not bud to mature virions, but is highly fusogenic and spreads extensively from cell to cell in a trypsindependent manner. Here, we changed the tryptic cleavage site of the fusion glycoprotein of this virus to a site susceptible to MMPs. The resulting recombinant virus was no longer activated by trypsin but spread efficiently in
\end{abstract}

cultured cells supplemented with MMP2 or MMP9 and in human tumor cell lines expressing these MMPs. Furthermore, the virus spread extensively in tumor cells xenotrasplanted to nude mice without disseminating to the surrounding normal cells, leading to the inhibition of the tumor growth in the mice. These results demonstrate the selective targeting and killing of human tumor cells by recombinant SeV technology and greatly advance the reemerging concept of oncolytic virotherapy, which currently appears to rely largely upon a natural preference of certain viruses for cancer cells.

Gene Therapy (2004) 11, 1137-1145. doi:10.1038/

sj.gt.3302272; Published online 15 April 2004

Keywords: Sendai virus; oncolytic virotherapy; tumor; MMP; matrix protein

\section{Introduction}

The idea of using infectious viruses as antitumor agents is again attracting attention in part because of progress in understanding virus-host interactions and because currently available chemotherapy is not completely satisfactory for many reasons, including the development of drug resistance. ${ }^{1-3}$ The oncolytic virotherapy strategies proposed to date rely largely upon the natural preference of certain viruses for cancer cells, as exemplified by Newcastle disease virus (NDV) and vesicular stomatitis virus, which belongs to the family Paramyxoviridae and the family Rhabdoviridae, respectively. Both of these families of viruses are characterized by a nonsegmented negative-strand RNA genome, and thus are also called mononegaviruses. Preclinical studies using viruses in other families have involved extensive efforts to increase selectivity for tumor cells by manipulation of the viruses by recombinant DNA technology. Examples of such efforts include attempts to change adenovirus attachment protein so that it recognizes tumor-specific cell surface molecules and deletion of herpesvirus accessory

Correspondence: $\operatorname{Dr} M$ Inoue, DNAVEC Research Inc., 1-25-11 Kannondai, Tsukuba-shi, Ibaraki 305-0856, Japan

${ }^{3}$ The first two authors contributed equally to this work

Received 18 September 2003; accepted 5 March 2004; published online 15 April 2004 genes that are indispensable for the viral life cycle in normal cells but likely dispensable in tumor cells. ${ }^{4,5}$

Sendai virus $(\mathrm{SeV})$, also a member of the Paramyxoviridae, infects most mammalian cells and directs highlevel expression not only in cultured cells but also in experimental animals of the genes within its genome that have been exploited for therapeutic use and vaccination. $^{6-10}$ A strong potential of NDV as a vaccine vector was also demonstrated. ${ }^{11} \mathrm{SeV}$ and most of the other mononegaviruses replicate independent of cellular nuclear functions and do not have a DNA phase in their lifecycle, and therefore are not considered to present a high risk of cell transformation by integration of the viral genetic information into the cellular genome. Thus, the feasibility of using $\mathrm{SeV}$ and other mononegaviruses as a novel class of vector is now increasing.

$\mathrm{SeV}$ displays a narrow spectrum of tissue tropism in susceptible hosts, growing in the respiratory tract of mice or in the allantoic cells of embryonated chicken eggs with little appreciable spreading to other tissues in these host organisms, even though its receptor is sialic acid residues, which are ubiquitous throughout the body. This restricted tropism is primarily due to the fact that the specific tissue proteases required for cleavage activation of viral fusion (F) glycoprotein, and thus for infectivity of progeny (the capacity to penetrate into and initiate infection of the next cell), are available only on the surface of those limited types of tissue. ${ }^{12}$ This concept 
of protease-dependent tropism of $\mathrm{SeV}$ was substantiated by the identification of responsible tissue proteases: the blood clotting factor Xa ectopically expressed by allantoic cells in ovo and secreted into the allantoic fluid, ${ }^{13}$ and tryptase Clara secreted into the airway epithelium in the lungs of rodents. ${ }^{14}$ The cleavage motif for these proteases in the fusion glycoprotein precursor $F_{0}$ is the sequence Q-S-R. Most tissue culture cells so far tested do not express SeV-activating proteases, and hence require a low concentration of exogenously added trypsin to allow SeV spreading. ${ }^{15}$ The receptor recognition is mediated by another envelope glycoprotein called hemagglutininneuraminidase $(\mathrm{HN})$.

The extracellular matrix (ECM) surrounding a tumor cell serves as a barrier that blocks tumor cell migration, infiltration and metastasis. Highly invasive, metastatic cancer cells express high levels of ECM-degrading enzymes such as matrix metalloproteinase (MMPs) and urokinase-type plasminogen activator (uPA). ${ }^{16,17}$ We have expanded the plasmid-based reverse genetics technology originally developed to manipulate the fulllength $\mathrm{SeV}$ genome ${ }^{18}$ in various directions, including deletion of certain viral genes, to generate nontransmissible, safer versions of SeV vector for gene therapy. ${ }^{19-21}$ Among them, M (matrix protein) gene-deleted $\mathrm{SeV}$ $(\mathrm{SeV} / \Delta \mathrm{M})$ is unique in that it does not bud into a mature particle in infected cells but rapidly spreads from cell to cell in the presence of trypsin, with the induction of massive syncytia followed by rapid cell death throughout the monolayer. ${ }^{22}$ We therefore considered it likely that $\mathrm{SeV} / \Delta \mathrm{M}$ would be more potent in killing solid tumor tissue than the wild-type $\mathrm{SeV}$ or any other deletion mutants. Here, we used the $\mathrm{SeV} / \Delta \mathrm{M}$ plasmid as the starting material and applied the concept of 'protease-dependent viral tropism' in order to generate a recombinant $\mathrm{SeV} / \Delta \mathrm{M}$ capable of 'tumor-specific protease-dependent oncolysis' at high efficiency.

\section{Results}

\section{Cell-to-cell spreading of $\mathrm{M}$ gene-deleted SeV}

Deletion of the viral $\mathrm{M}$ gene from SeV (Figure 1a) almost completely abolished virus maturation into particles and instead greatly facilitated cell-to-cell virus spreading via membrane fusion in the presence of $\mathrm{F}$ protein-activating trypsin ${ }^{22}$ (also see Figure 2a). Thus, the $\mathrm{M}$ gene-deleted $\mathrm{SeV}(\mathrm{SeV} / \Delta \mathrm{M}$ ) appeared to be more promising for killing the cells in a solid tumor than the wild-type SeV, because the facilitated cell fusion itself is cytotoxic in many cases. In addition, the absence of free infectious particles indicated that the mutant should undergo little undesired spreading to tissues distant from the initially infected cells. Therefore, the $\mathrm{SeV} / \Delta \mathrm{M}$ cDNA plasmid was used as the starting material for all subsequent manipulations to generate oncolytic SeVs. Virus growth and spreading were monitored by the expression of enhanced green fluorescent protein (GFP), whose openreading frame $(\mathrm{ORF})$ had been inserted into the viral genome in place of the M ORF (see Figure 1a).

\section{Attempt to alter the tryptic cleavage site in the SeV F protein to render it susceptible to MMPs}

We initially had to know whether or not it would be possible to alter the tryptic cleavage site of $\mathrm{SeV} \mathrm{F}$ a

\begin{tabular}{|c|c|c|c|c|c|c|}
\hline $\mathrm{SeV}$ & NP & $\mathbf{P}$ & $M$ & $F$ & $\mathrm{HN}$ & L \\
\hline $\mathrm{SeV} / \Delta \mathrm{M}$ & NP & $\mathbf{P}$ & GFP & $\mathbf{F}$ & $\mathrm{HN}$ & L \\
\hline & F2 & & & & F1 & \\
\hline
\end{tabular}

b

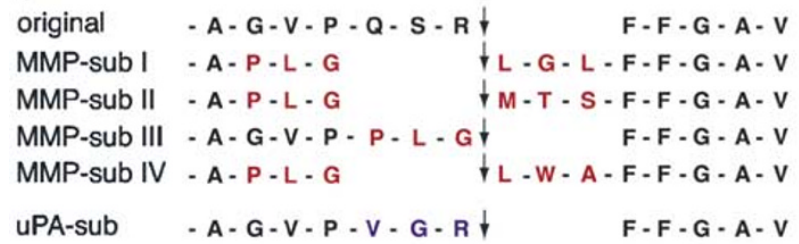

c

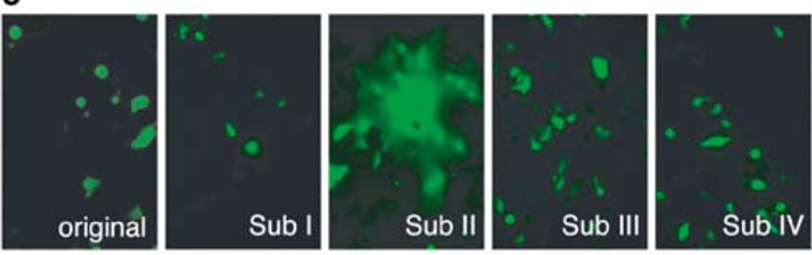

Figure 1 Gene maps of the wild-type $\mathrm{SeV}$ and $\mathrm{SeV} / \Delta \mathrm{M}$ (a), amino-acid changes at the $F$ protein cleavage site $(b)$ and the capacity of the resulting $F$ protein mutants to induce cell fusion (c). In SeV/LM, the ORF of the M protein was replaced by the GFP ORF. The amino-acid changes made to render the F protein an MMP substrate (subI-subIV) and those made to render it an $\mathrm{UPA}$ substrate are shown in red and blue, respectively. Cell fusion was analyzed by cotransfection into MMP-expressing HT1080 cells of the chimeric F/HN genes with the modified cleavage sequences and the plasmid-expressing GFP. Syncytia formation was observed $48 \mathrm{~h}$ after transfection under a fluorescence microscope.

glycoprotein to a site susceptible to MMPs. There are a number of known MMPs, and the cleavage sites recognized by the MMPs appear to consist of the tripeptide PLG followed by an additional tripeptide LGL or LWA, according to the findings of studies using synthetic substrates for MMP assays. ${ }^{23-25}$ Cleavage takes place between the two (upstream and downstream) tripeptides (Figure 1b). On the other hand, the natural cleavage of SeV F protein into F2 and F1 occurs between the $R$ and $F$ in Figure $1 b$, and the resulting N-terminal sequence of the F1 begins with FFG. A previous study demonstrated that the carbobenzoxy-FFG oligopeptide could specifically inhibit $\mathrm{SeV}$ fusion activity and infectivity in cultured cells, ${ }^{26}$ suggesting that the N-terminal FFG was specifically required for fusion capacity. Thus, the addition of LGL or LWA to the natural N-terminal FFG might impair fusion activity. Under these circumstances, the alteration of the tryptic cleavage site to an MMP-specific site without impairing fusion activity would not be easy. We therefore designed numerous sequences and show some of them (designated MMPsubI to MMP-subIV) in Figure 1b. These include MTS (subII), which was newly designed here by changing the MMP2- and MMP9-specific sequence MWS ${ }^{27}$ to MTS to accord with the favorable sequence for MMP9 substrates, Pro-X-X-Hy-(Ser/Thr), which was identified by phage display. ${ }^{28}$ MTS is less bulky and less hydrophobic than LGL or LWA, and may thus be less obstructive for fusion when it is attached to the N-terminus of F1 
after cleavage. Total omission of the downstream tripeptide specific for MMPs was also attempted so that FFG would appear at the $\mathrm{N}$ terminus. Designing uPAspecific substrate was relatively easy, because uPA and trypsin generally cleave after an R. Thus, only the two residues $Q$ and $S$ before the $R$ were changed to $V$ and $G$, respectively, to make the substrate more favorable for uPA (Figure 1b).

These and other modifications of the cleavage site were introduced into a plasmid encoding the $\mathrm{F}$ and $\mathrm{HN}$
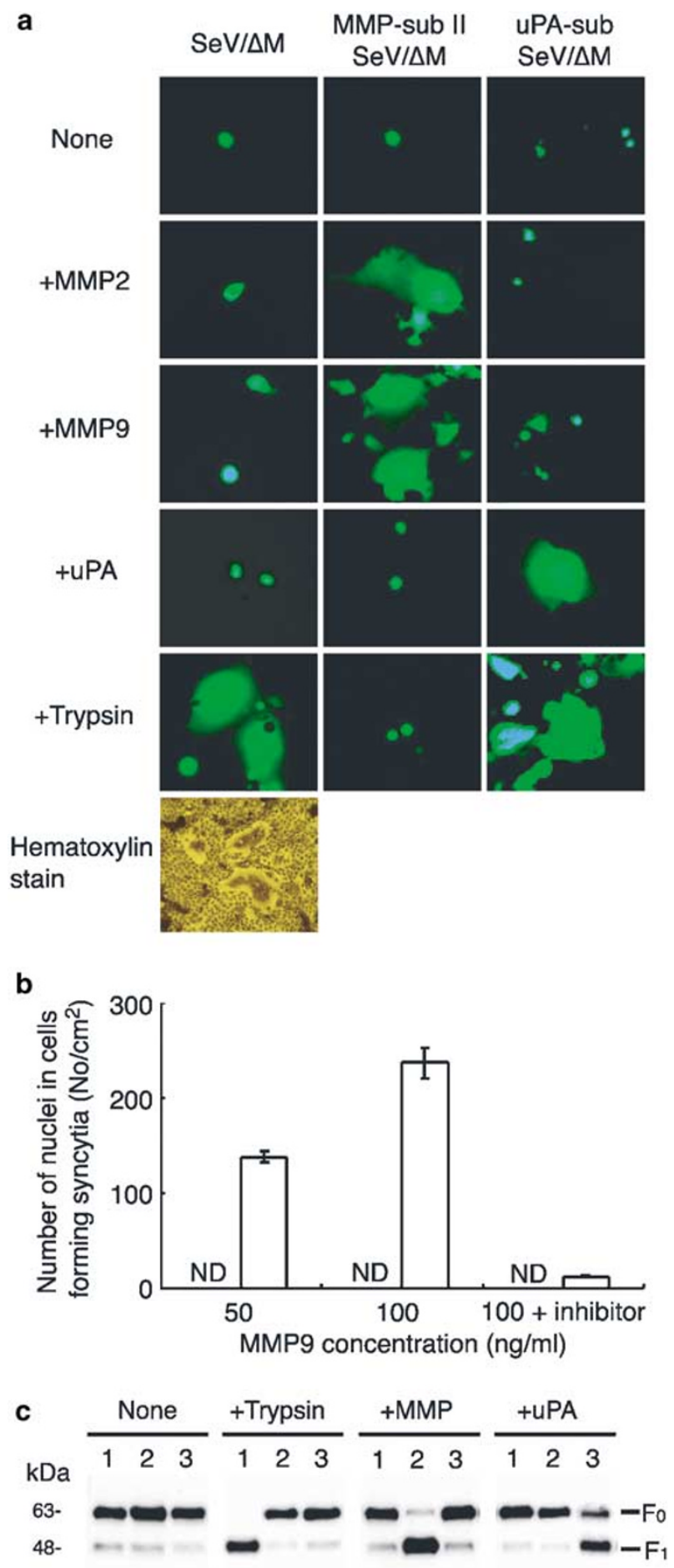

proteins as a fusion polypeptide. Each of the resulting plasmids was transfected, together with a GFP-expressing plasmid, pCAGGS/GFP, into human fibrosarcoma cell line HT1080 and human stomach cancer line MKN28, which expressed and secreted MMP and tissue-type plasminogen activator (tPA), respectively, at high levels. $^{29,30}$ tPA has the same cleavage specificity as uPA. As shown in Figure 1c, the F protein with the cleavage motif compatible with MMP-subII was fully fusion competent in the relevant target cell line, HT1080, whereas the other three substrates (subI, subIII and subIV) were not. While the subII mutant was fusion incompetent in the MKN28 cell line, the uPA-sub mutant was highly fusion inducing in this cell line but not in HT1080 (not shown).

\section{Recovery of SeV/AM viruses with modified cleavage} site and confirmation of their protease requirements According to the above results obtained by plasmidbased expression, the $\mathrm{SeV} / \Delta \mathrm{M}$ plasmid was engineered to possess the MMP-subII or uPA-sub cleavage motif, and infectious progeny were rescued in an $\mathrm{M}$ proteinexpressing helper cell line. ${ }^{22}$ The rescued viruses were examined for the protease requirement for the induction of cell fusion and virus spreading in LLC-MK 2 cells (Figure 2a). SeV / $\Delta \mathrm{M}$ with the MMP-subII cleavage motif in the $\mathrm{F}$ gene (MMP-subII SeV $/ \Delta \mathrm{M}$ ) spread extensively via cell-cell fusion in the presence of MMP2 or MMP9. The number of nuclei per syncytium reached as high as about 100-300, and syncytium formation was almost completely inhibited by the addition of the MMPinhibitor 1, 10 phenanthroline (Aldrich, Milwaukee, WI, USA) (Figure 2b). The same mutant could neither spread nor induce cell fusion in the presence of trypsin or uPA or in the absence of any protease (Figure 2a). The substrates of UPA and trypsin share an arginine at position -1 relative to the cleavage site, whereas the substrates of the MMPs do not have an arginine at this position. Thus, $\mathrm{SeV} / \Delta \mathrm{M}$ with $\mathrm{uPA}$ cleavage motif

Figure 2 Confirmation of alterations of protease requirement and cell tropism of SeV/AM by exogenously added proteases. (a) LLC-MK $K_{2}$ cells

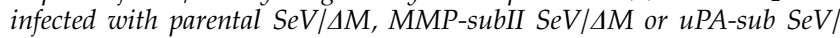
$\triangle M$ at an MOI of 0.02 were cultured with MMP2, MMP9, uPA $(0.1 \mu \mathrm{g} /$ $\mathrm{ml}$ each) or trypsin $(7.5 \mu \mathrm{g} / \mathrm{ml})$. The induction of cell fusion and cell-to-cell viral spreading was monitored by assessing the GFP expressed from each virus under a fluorescence microscope 4 days later. Cells infected with parental $\mathrm{SeV} / \Delta M$ and cultured with trypsin were also observed after hematoxylin staining. (b) Quantitative analysis of cell fusion of LLC-MK2 cells infected with MMP-subII SeV/DM in response to added MMP9. $M M P 9$ was added to the medium (serum-free MEM) immediately after the

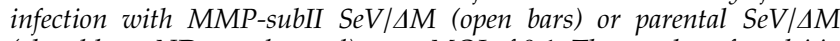
(closed bars, ND: not detected) at an MOI of 0.1. The number of nuclei in the cells forming syncytia was counted under a microscope 2 days after the infection. (c) Specific cleavage of the modified F proteins by treatment of the virions with proteases in vitro. Virus particles of the parental $\mathrm{SeV} / \Delta M$

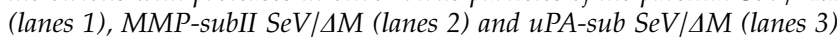
were prepared from the culture supernatants of an $M$ protein-expressing helper cell line after infection at an MOI of 3 (CIU/cell) and subsequent incubation for 2 days in the absence of any protease. The virus particles produced were pelleted by centrifugation at $18500 \mathrm{~g}$ for $3 \mathrm{~h}$, resuspended in PBS and incubated with trypsin $(7.5 \mu \mathrm{g} / \mathrm{ml}), \mathrm{MMP}-9(0.1 \mu \mathrm{g} / \mathrm{ml})$ or $u P A(0.1 \mu \mathrm{g} / \mathrm{ml})$ for $30 \mathrm{~min}$ at $37^{\circ} \mathrm{C}$. The controls (none) were incubated similarly in the absence of any protease. The viral proteins were then analyzed by Western blotting using an anti- $F_{1}$ antibody that recognized both $F_{0}$ and $F_{1}$ proteins. 
(uPA-sub SeV/ $/ \mathrm{M}$ ) spread in the presence of not only uPA but also trypsin, but not in the presence of the MMPs (Figure 2a). Spreading of the parental $\mathrm{SeV} / \Delta \mathrm{M}$ was possible only in the presence of trypsin. Trypsin might be able to cleave both the natural QSRFFG and artificial VGRFFG motifs (see Figure 1b) because it is a digestive enzyme with a broad specificity, whereas uPA might act only at the latter because it generally causes limited proteolysis with strict substrate specificity.

The highly selective protease dependency of virusinduced cell fusion and virus spreading nicely paralleled the cleavability of the $F_{0}$ precursor on the virions into $\mathrm{F}_{1}$ (Figure 2c) and $\mathrm{F}_{2}$ (not shown) only by the relevant proteases but not by any irrelevant ones. The $F_{0}$ of uPA-sub $\mathrm{SeV} / \Delta \mathrm{M}$ virions was not well cleaved by trypsin under the conditions employed, including $30 \mathrm{~min}$ of incubation with the enzyme, but incubation for a longer period $(4 \mathrm{~h})$ resulted in complete cleavage (not shown). This may account for the remarkable spreading of this mutant in the presence of trypsin (Figure 2a).

In perfect correlation with the above results obtained with exogenously added proteases, MMP-subII SeV / $\Delta \mathrm{M}$ spread extensively in a human fibrosarcoma cell line, HT1080, endogenously producing and secreting MMPs, but not in a human stomach cancer line, MKN28, producing tPA, whereas uPA-sub $\mathrm{SeV} / \Delta \mathrm{M}$ did the opposite, namely, spread in MKN28 but not in HT1080 (Figure 3a). Neither of the cell lines was permissive at all for the parental $\mathrm{SeV} / \Delta \mathrm{M}$.

A human pancreatic epithelioid carcinoma cell line, Panc I, which expresses MMP2 and MMP9 but at lower levels than HT1080 (Figure 3c), was unable to activate $\mathrm{MMP}$-subII SeV/ $\mathrm{M}$ (Figure $3 \mathrm{a}$ ). However, Panc I cells became permissive for this mutant (Figure $3 a$ and $b$ ) when MMP9 production was enhanced by treating the cells with a phorbol ester, phorbol 12-myristate 13acetate (PMA) (Figure 3c). In this experiment, SW620 (a human lymph node colorectal adenocarcinoma cell line) served as a control showing no stimulation of MMP production with PMA and no enhancement of virus spreading. Production of both MMP2 and MMP9 in HT1080 cells was enhanced by PMA (Figure 3c), but this enhancement resulted in only slight augmentation of MMP-sub II SeV / $\Delta \mathrm{M}$ spreading beyond the levels seen in the cells not treated with PMA (Figure 3b). SeV activation by the MMPs thus appeared to be nearly an

Figure 3 Confirmation of alterations of protease requirement and cell

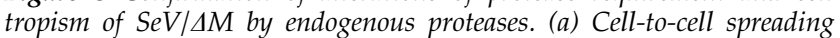
dependent on endogenous proteases expressed by tumor cells. Four different tumor cell lines, HT1080, Panc I, SW620 and MKN28, were

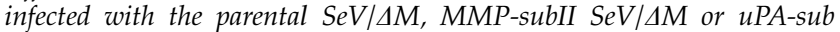
$\mathrm{SeV} / \triangle \mathrm{M}$ at an MOI of 0.02 and cultured in the medium containing $1 \%$ heat-inactivated fetal bovine serum, and cell fusion was observed 4 days later. Panc I cells were additionally analyzed to assess cell fusion following culturing with 20 nM PMA for 1 day. (b) Cell fusion of HT1080, Panc I and SW620 cells was quantified by counting the number of cells forming syncytia as observed under a microscope after infection and incubation for 4 days following culturing with (+) or without (-) $20 \mathrm{nM}$ PMA for 1 day. (c) Gelatin zymography ${ }^{47}$ of HT1080, Panc I and SW620 cells incubated with (+) or without (-) 20 nM PMA for 1 day and cultured in serum-free medium for 4 days. Gelatin zymography is a sensitive technique for the estimation of both active and latent types of $M M P-2$ and $M M P-9$ content in biological samples. PMA enhanced the levels of MMP9 in HT1080 and Panc I but not in SW620 cells. 'all or none' phenomenon with a critical threshold of the enzyme level. In addition, it should be emphasized that MMP2 and MMP9, together with MMP7, are likely more
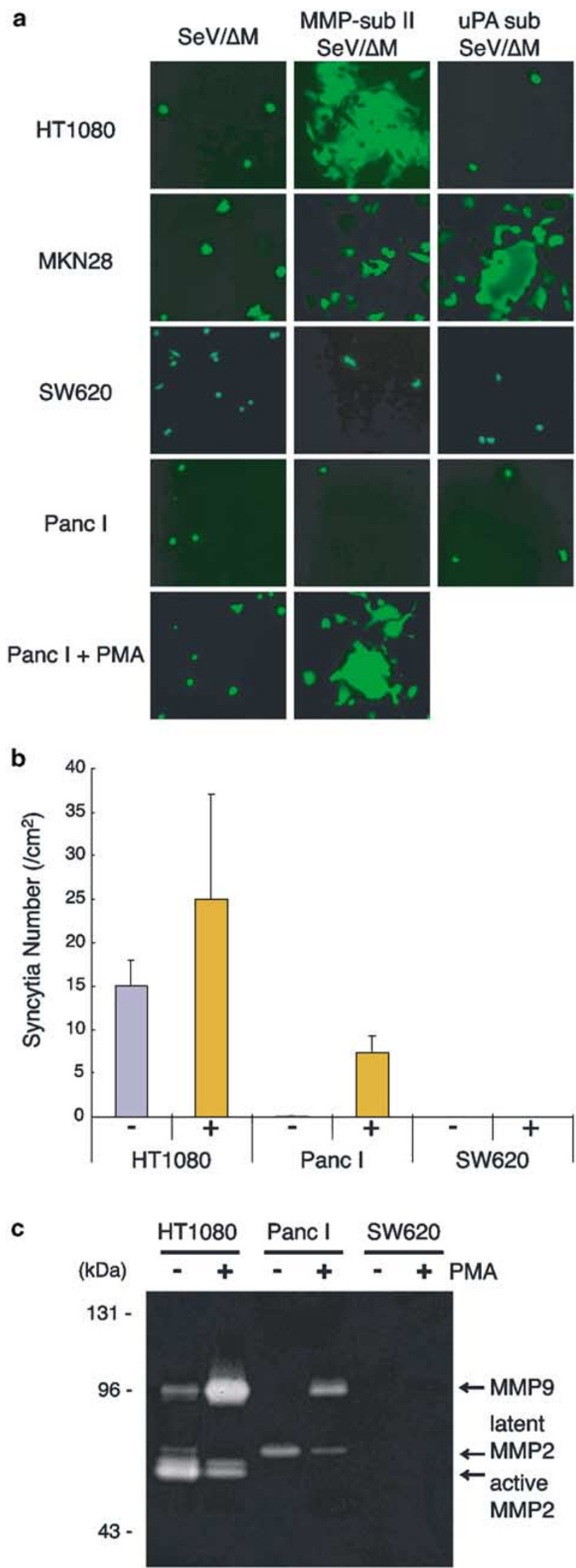
important for tumor metastasis than some 20 other known MMP species, since only the former three have the capacity to disrupt basement membranes. ${ }^{27,28}$

\section{Inhibition of HT1080 tumor growth in vivo by MMP- subll SeV/AM}

MMP-subII SeV / $\Delta \mathrm{M}$ was injected directly into the center of the mass of a HT1080 tumor that had been subcutaneously transplanted into nude mice and grown to an approximate diameter of $3-8 \mathrm{~mm}$. As control viruses we used not only the immediate parent, $\mathrm{SeV} /$ $\Delta \mathrm{M}$, of the mutant but also a standard SeV with a fulllength genome that harbored the GFP gene before its NP gene. After 2 days, light emission from the GFP protein in tumor cells was observed in the mice placed under a fluorescence microscope. GFP expressed from both of the control viruses was detected as small foci, likely at the injection site. In contrast, GFP expressed from MMPsubII SeV $/ \Delta \mathrm{M}$ spread throughout the entire tumor $(\times 1$ magnification in Figure 4a). Differences between MMPsubII $\mathrm{SeV} / \Delta \mathrm{M}$ and the control viruses were also remarkable at higher magnification $(\times 10)$. The boundaries between the tumor cells were not seen in the former, giving a highly amorphous impression, whereas in the controls infection foci were much smaller in size and separated from one another, and cell boundaries were clearly seen (Figure 4a). This strongly suggested vigorous viral spreading of the MMP-dependent mutant in the tumor, leading to efficient tumor lysis. Staining with anti-GFP was much less marked in the central area including the site of inoculation (arrow) than in the peripheral region in the MMP-subII SeV/ $\Delta \mathrm{M}$-infected tumor, whereas the central area was strongly positive for TUNEL staining and the peripheral region was negative or only poorly positive (Figure $4 b$ ). The TUNEL-positive cells are apoptotic ones characterized by internucleosomal DNA fragmentation. This result suggested that the cells in the peripheral area were actively supporting virus growth and viral gene expression, whereas those in the central area, which were probably infected earlier, were now dying via the apoptotic pathway. It should be noted that viral gene expression appeared to remain in the central area following infection by $\mathrm{SeV} / \Delta \mathrm{M}$, with no strong TUNEL staining in any area (Figure $4 \mathrm{~b}$ ). Furthermore, we quantitatively showed that MMP-subII SeV/ $\Delta \mathrm{M}$ strongly inhibited HT1080 tumor growth in the mice, whereas neither of the control viruses caused marked inhibition (Figure 4c).

The same in vivo experiment was performed using the other tumor line, SW620, that is low in MMP expression. After the injection of MMP-subII SeV/ $\mathrm{MM}$ into the SW620 tumor, GFP expressed from MMP-subII

Figure 4 Inhibition of HT1080 tumor growth in nude mice by MMP-

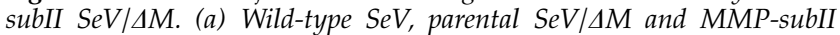
$\mathrm{SeV} / \Delta \mathrm{M}\left(5 \times 10^{7} \mathrm{CIU} / 50 \mu \mathrm{l}\right.$, each $)$ were injected once directly into the subcutaneously transplanted HT1080 tumors in nude mice. After 2 days, light emission from the GFP protein in tumor cells was observed externally under a fluorescence microscope. Magnification, $\times 1$ and $\times 10$. (b) TUNEL staining of cells. Arrows indicate the sites of virus injection. (c) Tumor volumes were calculated using the formula (volume $=\pi$ ) $6 \times a b c$ :(length $(a)$, width $(b)$, height $(c))$ and were expressed as the average $(n=7)$. Significantly different volumes were observed between the

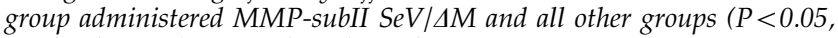
Student's t-test) at 8 and 10 days after injection.
$\mathrm{SeV} / \Delta \mathrm{M}$ spread slightly in the tumor (Figure 5a). Also, SW620 tumor growth in the mice was very slightly inhibited by MMP-subII SeV/ $\Delta \mathrm{M}$ injection (Figure 5c). However, immunohistochemical analysis showed that neither GFP- nor TUNEL-positive cells were significantly

a

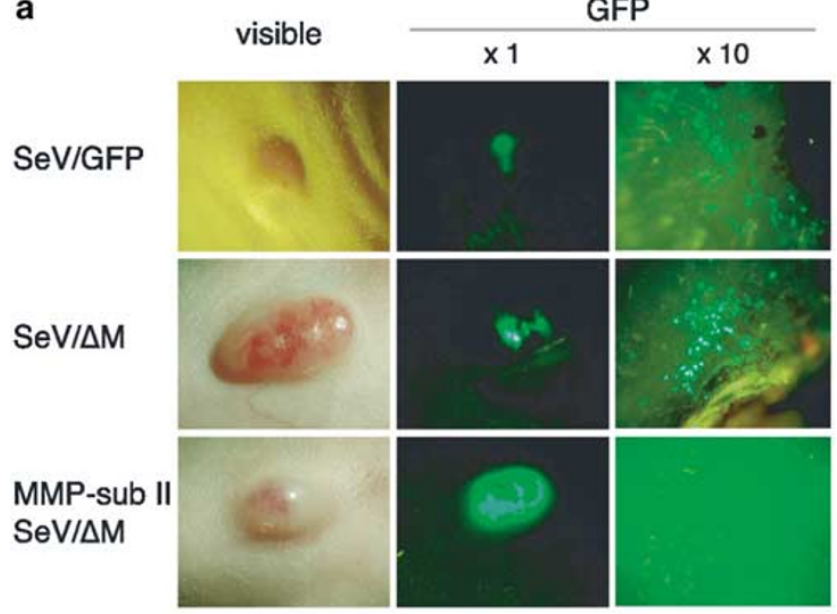

b

Anti-GFP

TUNNEL

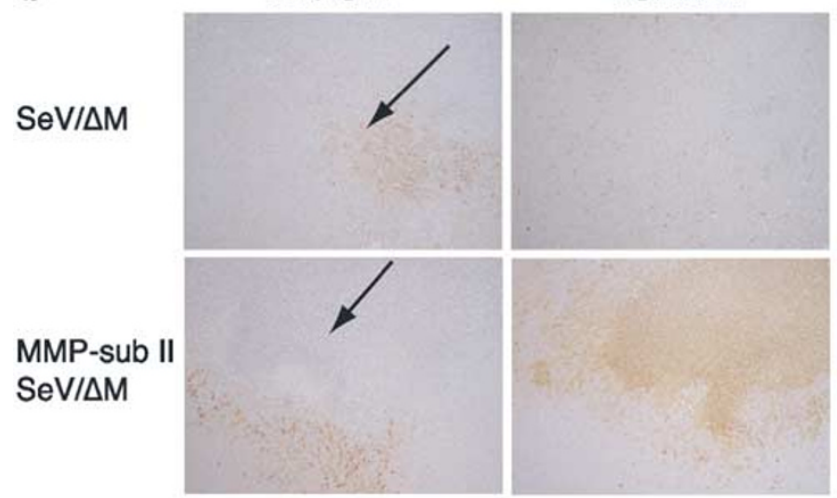

C

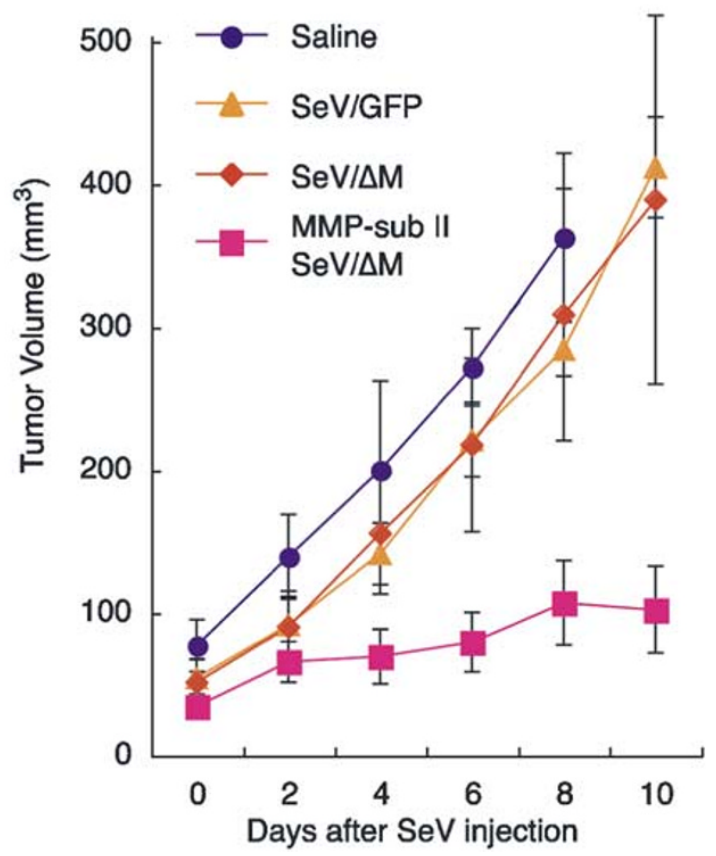


1142
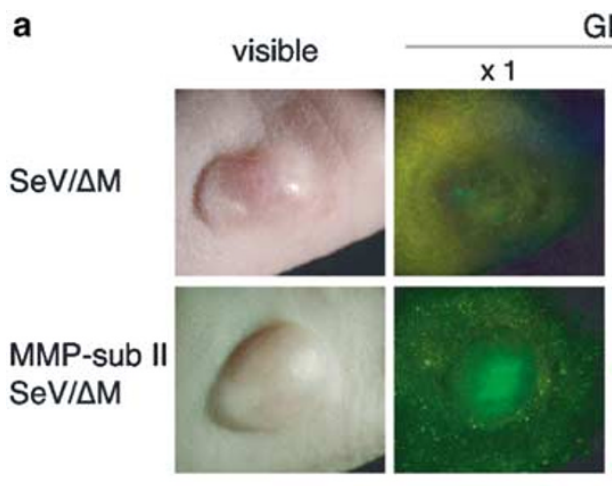

GFP

$\times 10$
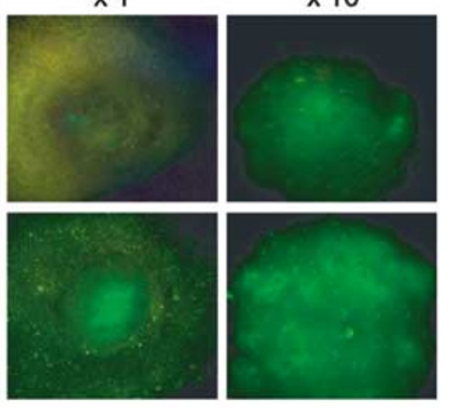

b

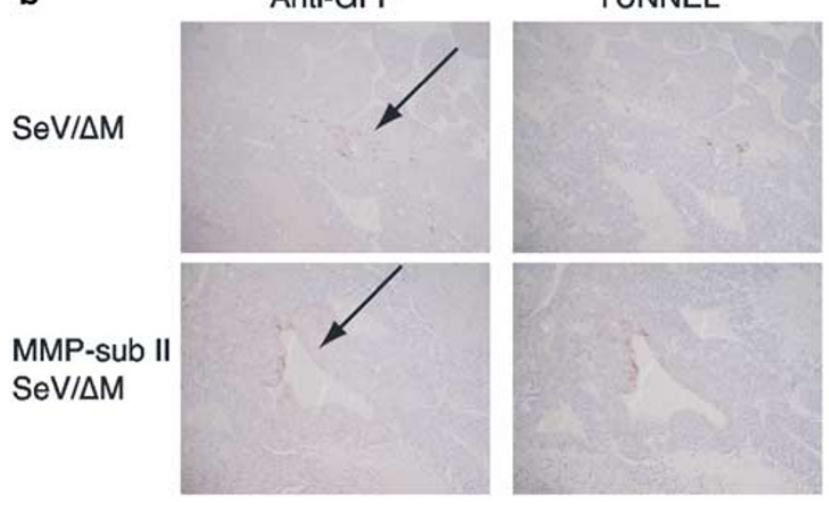

c

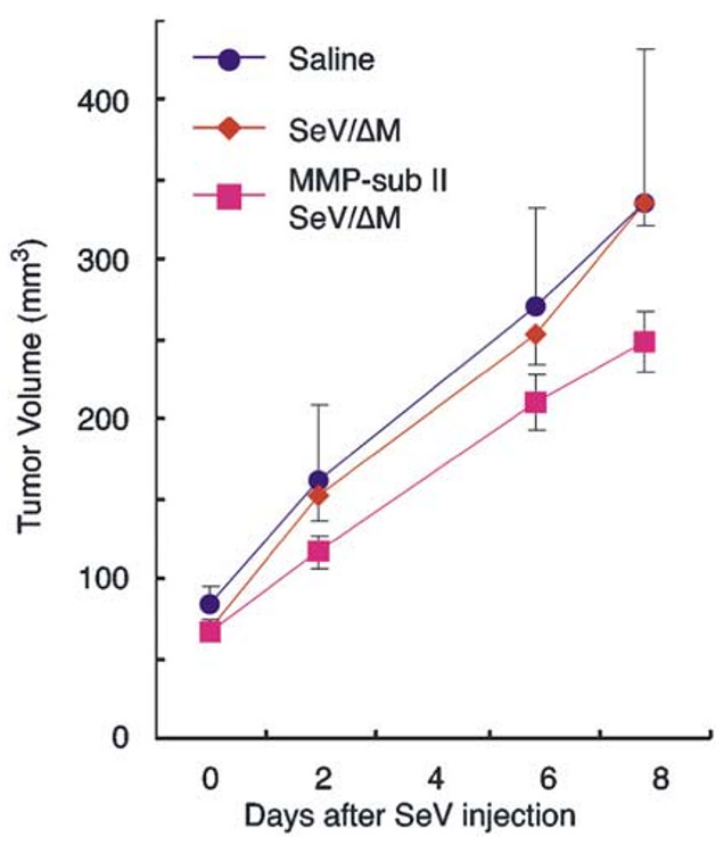

Figure 5 Restricted spreading of MMP-subII SeV/AM in the SW620 tumors in vivo. (a) Parental $\mathrm{SeV} / \Delta M$ and $M M P$-subII SeV/DM $\left(5 \times 10^{7} \mathrm{CIU} / 50 \mu \mathrm{l}\right.$, each) were injected once directly into the subcutaneously transplanted SW620 tumors in nude mice. After 2 days, light emission from the GFP protein in tumor cells was observed externally under a fluorescence microscope. (b) TUNEL staining of cells. Arrows indicate the sites of virus injection. (c) Tumor volumes expressed as the average $(n=5)$. No significant difference was observed between the respective groups. increased in either MMP-subII $\mathrm{SeV} / \Delta \mathrm{M}$ - or $\mathrm{SeV} / \Delta \mathrm{M}$ injected SW620 tumors (Figure 5b). As the expression of MMPs of SW620 cells is enhanced after the engraftment, ${ }^{31} \mathrm{MMP}$-subII $\mathrm{SeV} / \Delta \mathrm{M}$ would spread slightly in SW620 in vivo. However, viral spreading was limited in SW620 even in vivo, as the expression level of MMPs in SW620 was significantly lower than that in HT1080. In addition, no spreading was observed when MMP-subII $\mathrm{SeV} / \Delta \mathrm{M}$ was administered in normal tissues such as lung, trachea, nasal cavity and skin and muscle (data not shown). These results demonstrate the selective spreading of MMP-subII SeV $/ \Delta \mathrm{M}$ in the tumors that are high in MMP expression in vivo.

\section{Discussion}

We report here the generation of oncolytic recombinant SeVs that selectively target human tumor cells expressing MMP2, MMP9 and uPA by changing the tryptic cleavage-activation signal to a signal susceptible to those tumor-associated proteases. An additional alteration that we made was to delete the viral $M$ gene because this conferred on SeV the capacity to spread extensively from cell to cell with the induction of massive syncytia, and at the same time rendered the virus nontransmissible to distant tissues and thus safer than the wild type. ${ }^{22}$ Another M gene-deleted paramyxovirus, measles virus, was reported to propagate efficiently from cell to cell in an animal model (mouse brain). ${ }^{32}$ The successful recovery of MMP-subII SeV / $\Delta \mathrm{M}$ that selectively targeted and lysed MMP2- and MMP9-expressing tumor cells is of particular interest as these proteases represent two of a few proteases that have shown strong association with tumor metastasis among a large variety of MMP protease family members. Further improvement of MMP-subII $\mathrm{SeV} / \Delta \mathrm{M}$ is now being attempted by increasing the fusogenic activity and/or by the construction of vectors carrying therapeutic gene(s) such as immuno- and suicide genes, since MMP-subII $\mathrm{SeV} / \Delta \mathrm{M}$ did not succeed in complete eradication of HT1080 tumors in our experiments.

Johnson $e^{2} a^{33}$ succeeded in targeting the cytotoxicity of a fusogenic viral glycoprotein to an MMP-expressing glioma cell line. The strategy involved conditional inactivation and activation of the gibbon leukemia virus envelope protein. It was inactivated due to an extra peptide attached to its N-terminus with an MMPcleavable linker and became active (fusion competent and cytotoxic) only when it encountered an MMPexpressing cell that removed the peptide. However, their studies published so far were limited to plasmid-based expression of the engineered glycoproteins and not expression in the context of the viral replicon of either a full-length or defective genome. Thus, their studies and ours are largely different from each other in both conceptual and practical details, although both depend on MMP-substrate interaction. Aside from this, the measles virus was modified for the targeting to tumor cells by linking a single-chain antibody recognizing tumor-cell-specific proteins to its envelope protein..$^{34,35}$ Although it affects only targeting and not tumor-cellspecific spreading, such modification (for targeting) could be combined with one of our vectors (for tumorcell-specific spreading), such as MMP-subII SeV/ $\Delta \mathrm{M}$. 
Our strategy is theoretically and practically applicable to a large number of other paramyxoviruses, including NDV, which is now under extensive clinical trials based on its natural preference for cancer cells, and members of other virus families, such as influenza viruses, because they share the same cleavage-activation mechanism of the envelope proteins for initiation and spread of infection $^{12,36}$ and because recombinant DNA technologies have been established for them. The matrix gene deletion from the genome may not always be necessary but would be advantageous when targeting a tumor mass.

A key issue in the application to actual medicine of the findings obtained here using clonal tumor cell lines is to individualize ${ }^{37}$ the approach by identifying the protease species in actual tumors of individual patients. There is increasing evidence suggesting that the higher the protease level at diagnosis the worse the prognosis, 27,38 and we have shown here that there would be a critical threshold of the enzyme levels required for virus activation. Thus, not only the species but also the amounts of the proteases involved in the actual tumor will have to be included in 'individualization'. The protease species as well as their levels would be relatively easy to determine by the analysis of biopsy materials from individual patients by conventional immunohistochemistry, ELISA and other assay methods. ${ }^{39-42}$ Once they are determined, it would also be easy to generate appropriate protease activation mutants of $\mathrm{SeV}$ and related envelope viruses. The safety of recombinant $\mathrm{SeVs}$ is another key issue. They so far do not appear to cause any serious problems or symptoms in rhesus monkeys after administration in various ways, including intramuscular injection as well as intranasal inoculation (unpublished data).

\section{Materials and methods}

\section{Cell lines}

The cell lines HT1080 (human fibrosarcoma), Panc I (human pancreatic epithelioid carcinoma), SW620 (human lymph node colorectal adenocarcinoma) and

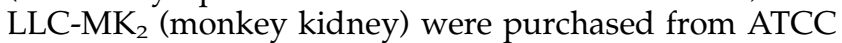
(Manassas, VA, USA). The human stomach cancer cell line MKN28 was purchased from the Institute of Physical and Chemical Research (Tsukuba, Japan).

\section{Construction of plasmids expressing SeV $F$ and HN proteins as a fusion polypeptide with modified cleavage site sequences in the $F$ protein}

The $\mathrm{F}$ protein is a direct mediator of cell fusion but requires coexpression of the receptor-binding $\mathrm{HN}$ protein from a second plasmid for the actual expression of fusion capacity. ${ }^{43,44}$ Alternatively, we found that the expression of the $\mathrm{F}$ and $\mathrm{HN}$ proteins as a single polypeptide connected by 30 unrelated amino acids was also fusion inducing (details will be published elsewhere). The plasmid for this F-HN-coupled expression was constructed by the amplification of the $F$ and $\mathrm{HN}$ genes in the plasmid pSeV18 $+\mathrm{b}^{18}$ by polymerase chain reaction and cointroduction of the amplified genes into the mammalian expression vector pCAGGS. ${ }^{45}$ The primer pair specific for the $\mathrm{F}$ gene was $\mathrm{Fu}-\mathrm{F}\left(5^{\prime}-\right.$ ATCCGAATTCAGTTCAATGACAGCATATATCCAGAG-3') and $\mathrm{Fu}-\mathrm{R}$ (5'-ATCCGCGGCCGCCGGTCATCTGGAT TACCCATTAGC- $3^{\prime}$ ), and that for the $\mathrm{HN}$ gene was HN-F( + linker) (5'-ATCCGCGGCCGCAATCGAGGGA AGGTGGTCTGAGTTAAAAATCAG GAGCAACGAC GGAGGTGAAGGACCAGAGGACGCCAACGACCCA CGGGGAAAGGGGTGAACACATCCATATCCAGCCA TCTCTACCTGTTTATGGACAGAGGGTTAGG-3') and HN-R (5'-ATCCGCGGCCGCTTAAGACTCGGCCTTG CATAA- $3^{\prime}$ ). The amplified $\mathrm{F}$ and $\mathrm{HN}$ genes were digested with NotI and XhoI (for the F gene) or NotI (for the HN gene) and ligated together with pCAGGS digested with NotI and XhoI. Conversion of amino-acid sequences around the cleavage site of $\mathrm{F}$ protein was performed using a QuikChange site-directed mutagenesis kit (Stratagene, La Jolla, CA, USA) according to the manufacturer's protocol. The primer pairs used for mutagenesis were pMMP \#1-F (5'-CAAAATGCCGGT GCTCCCCcGTtGgGATTCTTCGGTGCTGTGATT-3') and pMMP \#1-R (5'-AATCACAGCACCGAAGAATCc CaACgGGGGAGCACCGGCATTTTG-3') for MMP-subI; pMMP \#2-F (5'-CTGTCACCAATGATACGACACAAA ATGCCccTctTggCatGaCGAGtTTCTTCGGTGCTGTGAT TGGTACTATC- $\left.3^{\prime}\right)$ and pMMP \#2-R (5'-GATAGTACCA ATCACAGCACCGAAGAAaCTCGtCatGccAagAggGG CATTTTGTGTCGTATCATTGGTGACAG-3') for MMPsubII; pMMP \#3-F (5'-GTCACCAATGATACGACACA AAATGCCccTctTggCctGtgGgcaTTCTTCGGTGCTGT GATTGGTACTATC-3') and pMMP \#3-R (5'-GATAG TACCAATCACAGCACCGAAGAAtgcCcaCagGccAa gAggGGCATTTTGTGTCGTATCATTGGTGAC-3') for MMP-subIII; pMMP \#4-F (5'-CTGTCACCAATGATAC GACACAAAATGCCccTctTggCCtGggGttA TTCTTCGGT GCTGTGATTGGTACTATCG-3') and pMMP \#4-R (5'CGATAGTACCAATCACAGCACCGAAGAATaaCccCa GGccAagAggGGCATTTTGTGTCGTATCATTGGTGA CAG-3') for MMP-subIV; and puPA-F (5'-GACACAA AATGCCGGTGCTCCCgtGggGAGATTCTTCGGTGCTG TGATTG-3') and puPA-R (R: 5'-CAATCACAGCACC GAAGAATCTCccCacGGGAGCACCGGCATTTTGTGTC-3') for uPA-sub. Lower case letters in the primer sequences described above represent the substituted nucleotides.

Construction and amplification of F-modified SeV/AM The parental plasmid $\mathrm{SeV} / \Delta \mathrm{M}$, which is pSeV18 $+/ \Delta \mathrm{M}$ GFP with a bacteriophage T7 promoter, ${ }^{22}$ was digested with SalI and NheI, and the resulting fragment $(9.6 \mathrm{~kb})$ was subcloned into LITMUS 38 (New England Biolabs. Beverly, MA, USA). Site-directed mutagenesis was performed on this plasmid. Recovery and amplification of F-modified $\mathrm{SeV} / \Delta \mathrm{M}$ from cloned cDNA were performed essentially as described, ${ }^{19-21}$ using recombinant vaccinia virus expressing T7 RNA polymerase ${ }^{46}$ and the $\mathrm{SeV} \mathrm{M}$ protein-expressing $\mathrm{LLC}-\mathrm{MK}_{2}$ packaging cell line. ${ }^{22}$ Type IV collagenase $(5 \mathrm{U} / \mathrm{ml})$ of Clostridium histolyticum (ICN, Aurora, OH, USA) and $7.5 \mu \mathrm{g} / \mathrm{ml}$ of trypsin were added to the medium to activate the modified $\mathrm{F}$ protein in the cases of MMP-subII SeV $/ \Delta \mathrm{M}$ and $\mathrm{uPA}$-sub SeV $/ \Delta \mathrm{M}$, respectively. The amplification of recovered viruses was also carried out using the $M$ expressing LLC-MK ${ }_{2}$ packaging cell line. ${ }^{22}$

\section{Cell fusion analysis by transfection of $F / H N$-expressing plasmids}

The above-described expression vector, pCAGGS, carrying the individual $\mathrm{F} / \mathrm{HN}$ fusion gene with a modified 
cleavage sequence in the $F$ protein was transfected together with pCAGGS/GFP expressing the enhanced GFP into MMP-expressing HT1080 cells using the transfection reagent FuGENE6 (Roche, Basel, Switzerland). Syncytia formation was observed $48 \mathrm{~h}$ after transfection under a fluorescence microscope (Leica, Wetzlar, Germany).

\section{Cell fusion analysis following infection with F-modified $\mathrm{SeV} / \Delta \mathrm{M}$}

LLC-MK ${ }_{2}$ cells infected with the parental $\mathrm{SeV} / \Delta \mathrm{M}$, MMP-subII SeV/ $\Delta \mathrm{M}$ or uPA-sub SeV/ $\Delta \mathrm{M}$ at an MOI of 0.02 were cultured in serum-free MEM containing MMP2, MMP9 or uPA $(0.1 \mu \mathrm{g} / \mathrm{ml}$, each) or trypsin $(7.5 \mu \mathrm{g} / \mathrm{ml})$. For the inhibition study, the MMP-inhibitor 1,10 phenanthroline was added to the medium at a final concentration of $12.5 \mu \mathrm{M}$. To quantify the fused cells, the number of nuclei in cells forming syncytia was counted after culturing in serum-free MEM containing a series of concentrations of collagenase or MMP-9. Tumor cell lines HT1080, Panc I, SW620 and MKN28, which express the proteases indicated in the text endogenously, were also infected with these viruses at an MOI of 0.02, and cultured in the medium containing $1 \%$ heat-inactivated fetal bovine serum. In both of these exogenous and endogenous protease requirement studies, cell fusion was observed under a fluorescence microscope (Leica, Wetzlar, Germany) 4 days after infection.

\section{Western blotting}

SDS-PAGE and Western blotting were carried out according to the method described..$^{22} \mathrm{~A}$ rabbit polyclonal anti- $\mathrm{F}_{1}$ antibody was raised against three mixed synthetic peptides of SeV F protein, that is, (1) FFGAVIGT + Cys, (2) EAREAKRDIALIK and (3) CGTGRRPISQDRS, corresponding to amino acids 117-124, 143-155 and 401-413 of $\mathrm{SeV}-\mathrm{F}$, respectively. Immunization was carried out after conjugation of the peptides to keyhole limpet hemocyanin. Incubation of the Western blotting membrane with the anti- $\mathrm{F}_{1}$ primary antibody was followed by incubation with the second antibody, anti-rabbit IgG conjugated with HRP (ICN, Aurola, OH, USA). The proteins on the membrane were detected by a chemiluminescence method (ECL Western blotting detection reagents; Amersham Biosciences, Uppsala, Sweden).

\section{In vivo study}

HT1080 or SW620 cells $\left(5 \times 10^{6}\right.$ cells/mouse $)$ were injected subcutaneously into the right back of Balb/c nude mice (Charls River Co, Kanagawa, Japan). The engrafted tumors developed to $3-8 \mathrm{~mm}$ in diameter by 8-9 days after transplantation. The mice were then divided into four groups ( $n=5$ or 7 /group) that received intratumoral injection of saline, wild-type $\mathrm{SeV}$, parental $\mathrm{SeV} / \Delta \mathrm{M}$ or MMP-subII $\mathrm{SeV} / \Delta \mathrm{M}\left(5 \times 10^{7}\right.$ cell infectious unit (CIU)) in a $50 \mu \mathrm{l}$ volume using a 26-gauge needle.

\section{Immunohistochemistry}

For anti-GFP antibody staining (Molecular Probes, Eugene, OR, USA) and Apotag peroxidase in situ apoptosis detection (Intergen Co., Norcross, GA, USA), tumors were removed, fixed with $4 \%$ paraformaldehyde and embedded in paraffin 2 days after injection of each virus. In all, 5 - $\mu$ m-thick sections were used for stainings.

\section{Acknowledgements}

We thank B Moss, I Saito, H Iba and M Kobayashi for supplying experimental materials essential for this study; $\mathrm{T}$ Kanaya and $\mathrm{H}$ Ban for their excellent technical assistance and A Kato and Y Ueda for helpful discussions.

\section{References}

1 Kirn D, Martuza RL, Zwiebel J. Replication-selective virotherapy for cancer: biological principles, risk management and future directions. Nat Med 2001; 7: 781-787.

2 Mullen JT, Tanabe KK. Viral oncolysis. Oncologist 2002; 7: 106-119.

3 Sinkovics J, Horvath J. New developments in the virus therapy of cancer: a historical review. Intervirology 1993; 36: 193-214.

4 Antonio Chiocca E. Oncolytic viruses. Nat Rev Cancer 2002; 2: 938-950.

5 Ring CJ. Cytolytic viruses as potential anti-cancer agents. J Gen Virol 2002; 83: 491-502.

6 Yonemitsu Y et al. Efficient gene transfer to airway epithelium using recombinant Sendai virus. Nat Biotechnol 2000; 18: 970-973.

7 Matano $\mathrm{T}$ et al. Rapid appearance of secondary immune responses and protection from acute CD4 depletion after a highly pathogenic immunodeficiency virus challenge in macaques vaccinated with a DNA prime/Sendai virus vector boost regimen. J Virol 2001; 75: 11891-11896.

8 Shiotani A et al. Skeletal muscle regeneration after insulin-like growth factor I gene transfer by recombinant Sendai virus vector. Gene Therapy 2001; 8: 1043-1050.

9 Masaki I et al. Angiogenic gene therapy for experimental critical limb ischemia: acceleration of limb loss by overexpression of vascular endothelial growth factor 165 but not of fibroblast growth factor-2. Circ Res 2002; 90: 966-973.

10 Shirakura $\mathrm{M}$ et al. Sendai virus vector-mediated gene transfer of glial cell line-derived neurotrophic factor prevents delayed neuronal death after transient global ischemia in gerbils. Exp Anim 2003; 52: 119-127.

11 Nakaya $\mathrm{T}$ et al. Recombinant Newcastle disease virus as a vaccine vector. J Virol 2001; 75: 11868-11873.

12 Nagai Y. Protease-dependent virus tropism and pathogenicity. Trends Microbiol 1993; 1: 81-87.

13 Gotoh B et al. An endoprotease homologous to the blood clotting factor $X$ as a determinant of viral tropism in chick embryo. EMBO J 1990; 9: 4189-4195.

14 Kido $\mathrm{H}$ et al. Isolation and characterization of a novel trypsinlike protease found in rat bronchiolar epithelial Clara cells. A possible activator of the viral fusion glycoprotein. J Biol Chem 1992; 267: 13573-13579.

15 Homma M, Ouchi M. Trypsin action on the growth of Sendai virus in tissue culture cells. 3. Structural difference of Sendai viruses grown in eggs and tissue culture cells. J Virol 1973; 12: $1457-1465$.

16 Cox G, O'Byrne KJ. Matrix metalloproteinases and cancer. Anticancer Res 2001; 21: 4207-4219.

17 Andreasen PA, Egelund R, Petersen HH. The plasminogen activation system in tumor growth, invasion, and metastasis. Cell Mol Life Sci 2000; 57: 25-40.

18 Kato A et al. Initiation of Sendai virus multiplication from transfected cDNA or RNA with negative or positive sense. Genes Cells 1996; 1: 569-579.

$19 \mathrm{Li} \mathrm{HO}$ et al. A cytoplasmic RNA vector derived from nontransmissible Sendai virus with efficient gene transfer and expression. J Virol 2000; 74: 6564-6569.

20 Hirata $\mathrm{T}$ et al. An improved method for recovery of F-defective Sendai virus expressing foreign genes from cloned cDNA. J Virol Methods 2002; 104: 125-133. 
21 Inoue $\mathrm{M}$ et al. Non-transmissible virus-like particle formation of F-deficient Sendai virus shows temperature-sensitivity and can be reduced by mutations on M and HN protein. J Virol 2003; 77: 3238-3246.

22 Inoue $\mathrm{M}$ et al. A new Sendai virus vector deficient in the matrix gene does not form virus particles and shows extensive cell-tocell spreading. J Virol 2003; 77: 6419-6429.

23 Stack MS, Gray RD. Comparison of vertebrate collagenase and gelatinase using a new fluorogenic substrate peptide. J Biol Chem 1989; 264: 4277-4281.

24 Darlak $\mathrm{K}$ et al. Thiol-based inhibitors of mammalian collagenase. Substituted amide and peptide derivatives of the leucine analogue, 2-[(R,S)-mercaptomethyl]-4-methylpentanoic acid. J Biol Chem 1990; 265: 5199-5205.

25 Knight CG, Willenbrock F, Murphy G. A novel coumarinlabelled peptide for sensitive continuous assays of the matrix metalloproteinases. FEBS Lett 1992; 296: 263-266.

26 Richardson CD, Scheid A, Choppin PW. Specific inhibition of paramyxovirus and myxovirus replication by oligopeptides with amino acid sequences similar to those at the N-termini of the F1 or HA2 viral polypeptides. Virology 1980; 105: 205-222.

27 Curran S, Murray GI. Matrix metalloproteinases: molecular aspects of their roles in tumour invasion and metastasis. Eur J Cancer 2000; 36: 1621-1630.

28 Friedberg $\mathrm{MH}$ et al. Specific matrix metalloproteinase profiles in the cerebrospinal fluid correlated with the presence of malignant astrocytomas, brain metastases, and carcinomatous meningitis. Cancer 1998; 82: 923-930.

29 Morodomi $\mathrm{T}$ et al. Purification and characterization of matrix metalloproteinase 9 from U937 monocytic leukaemia and HT1080 fibrosarcoma cells. Biochem J 1992; 285 (Part 2): 603-611.

30 Koshikawa N, Yasumitsu H, Umeda M, Miyazaki K. Multiple secretion of matrix serine proteinases by human gastric carcinoma cell lines. Cancer Res 1992; 52: 5046-5053.

31 Mc Donnell S et al. Metastatic and non-metastatic colorectal cancer (CRC) cells induce host metalloproteinase production in vivo. Clin Exp Metast 1999; 17: 341-349.

32 Cathomen $\mathrm{T}$ et al. A matrix-less measles virus is infectious and elicits extensive cell fusion: consequences for propagation in the brain. EMBO J 1998; 17: 3899-3908.

33 Johnson $\mathrm{KJ}$ et al. Targeting the cytotoxicity of fusogenic membrane glycoproteins in gliomas through proteasesubstrate interaction. Gene Therapy 2003; 10: 725-732.

34 Bucheit $\mathrm{AD}$ et al. An oncolytic measles virus engineered to enter cells through the CD20 antigen. Mol Ther 2003; 7: 62-72.

35 Peng KW et al. Oncolytic measles viruses displaying a singlechain antibody against CD38, a myeloma cell marker. Blood 2003; 101: 2557-2562.

36 Klenk HD, Garten W. Host cell proteases controlling virus pathogenicity. Trends Microbiol 1994; 2: 39-43.

37 Gromeier M. Viruses for treating cancer. ASM News 2002; 68: 438-445.

38 Cantero D et al. Enhanced expression of urokinase plasminogen activator and its receptor in pancreatic carcinoma. $\mathrm{Br} J$ Cancer 1997; 75: 388-395.

39 Zucker $\mathrm{S}$ et al. Measurement of matrix metalloproteinases and tissue inhibitors of metalloproteinases in blood and tissues. Clinical and experimental applications. Ann NY Acad Sci 1999; 878: 212-227.

40 Hayasaka A et al. Elevated plasma levels of matrix metalloproteinase-9 (92-kd type IV collagenase/gelatinase B) in hepatocellular carcinoma. Hepatology 1996; 24: 1058-1062.

41 Nomura $\mathrm{H}$ et al. Expression of membrane-type matrix metalloproteinase in human gastric carcinomas. Cancer Res 1995; 55: 3263-3266.

42 Ishikawa N, Endo Y, Sasaki T. Inverse correlation between mRNA expression of plasminogen activator inhibitor-2 and lymph node metastasis in human breast cancer. Jpn J Cancer Res 1996; 87: 480-487.

43 Lamb RA, Kolakofsky D. Paramyxoviridae: the viruses and their replication. In: Fields BN, Knipe DM and Howley PM (ed). Fields Virology. Lippincott-Raven: Philadelphia, PA, 1996, pp 1177-1204.

44 Heath TD, Martin FJ, Macher BA. Association of gangliosideprotein conjugates into cell and Sendai virus. Requirement for the HN subunit in viral fusion. Exp Cell Res 1983; 149: 163-175.

45 Niwa H, Yamamura K, Miyazaki J. Efficient selection for highexpression transfectants with a novel eukaryotic vector. Gene 1991; 108: 193-199.

46 Fuerst TR, Niles EG, Studier FW, Moss B. Eukaryotic transientexpression system based on recombinant vaccinia virus that synthesizes bacteriophage T7 RNA polymerase. Proc Natl Acad Sci USA 1986; 83: 8122-8126.

47 Kinoh $\mathrm{H}$ et al. MT-MMP, the cell surface activator of proMMP-2 (pro-gelatinase A), is expressed with its substrate in mouse tissue during embryogenesis. J Cell Sci 1996; 109: 953-959. 